\title{
14
}

\section{HPLC-MS characterisation of adsorbed residues from Early Iron Age ceramics, Gordion, Central Anatolia}

\author{
Todd Craig \\ Peter Grave ${ }^{1}$ \\ Stephen Glover ${ }^{2}$
}

\author{
1 Department of Archaeology and Palaeoanthropology \\ University of New England \\ Armidale NSW 2351, Australia \\ ${ }^{2}$ School of Biological, Biomedical and Molecular Sciences \\ University of New England \\ Armidale, NSW, 2351, Australia
}

\section{Abstract}

High performance liquid chromatography with mass spectrometry (HPLC-MS) is a powerful method for characterising modern fats and oils at the molecular level (triacylglycerols). It is a technique that should have great potential for the analysis of archaeological fatty residues. However, its archaeological potential has yet to be systematically evaluated. This paper presents the results of an HPLC-MS study of food residues adsorbed into archaeological ceramics. Experimentally three classes of materials were studied: raw plant and animal foods likely to be available to the prehistoric population of Anatolia (Turkey), the same foods after cooking and archaeological residues from Late Bronze and Early Iron Age (ca 1500-900 BCE) contexts from ceramics excavated at the site of Gordion, Central Turkey. Modern foods were used as a baseline; modern cooked residues provided a measure of the effects of cooking on the same fatty residues. These datasets were then compared to the HPLC-MS results for the archaeological residues. The study found that HPLC-MS does offer important new information, but does not provide a 'magic bullet'. Like established techniques using gas chromatography and mass spectrometry, it is best used in tandem with other techniques in a multi-stranded approach to archaeological residue characterisation and identification.

Keywords: HPLC-MS; residue identification; lipids; cooking residues; fatty acids; triacylglycerols; Gordion 


\section{Introduction}

Fatty residues recovered from within the porous fabrics of archaeological ceramics have been studied for almost 30 years. Condamin and coworkers (1976) first demonstrated that the porous fabric of earthenware ceramics provides an excellent microenvironment for the preservation of fatty residues. Initially, chemical exploration of archaeological residues focused on fatty acid derivatives due to their archaeological ubiquity and analytic simplicity (Condamin et al. 1976, Morgan et al. 1984, Patrick et al. 1985). In simple terms fatty acids are hydrocarbon chains with a terminal carboxyl group (Markley 1960). These hydrocarbon chains occur in a range of configurations. However, straight-chain saturated fatty acids and carbon-carbon double bond unsaturated fatty acids are most common (Figure 1b, 1c) (Christie 2003). The relative ubiquity of most fatty acid species in modern plant and animal products limits their diagnostic utility (Hilditch and Williams 1964). Less than 25 fatty acid species can account for more than $90 \%$ of fatty acids in nature. Of these, some are highly susceptible to degradation and therefore unlikely to survive over archaeological time (Evershed et al. 1992, Evershed et al. 2001).

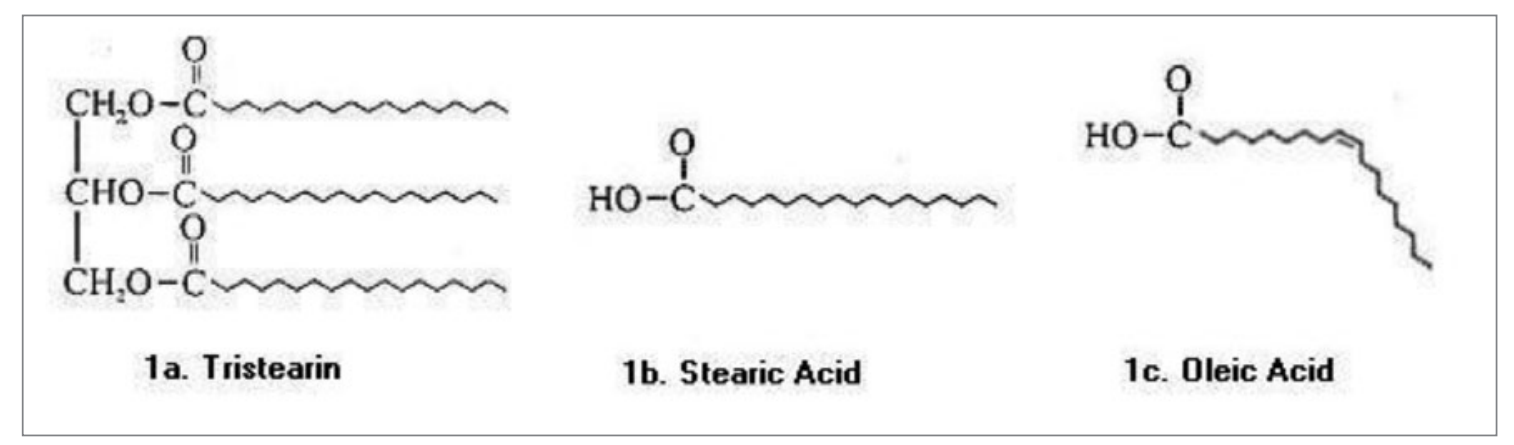

Figure 1. 1a. tristearin; 1b. stearic acid; 1c. oleic acid. Adapted from Evershed et al. (2001).

Improvements in column chromatography and the increasingly common technique of gas chromatography with mass spectrometry (GC-MS) in laboratories in the 1990s led to the rapid expansion of types of archaeological molecules analysed, including fatty acids (Copley et al. 2005, Craig et al. 2005, Eerkens 2005, Evershed et al. 2002, Kimpe et al. 2004, Malainey et al. 1999), waxes (Charters and Evershed 1997, Evershed et al. 1997, Gariner et al. 2002), alcohols (Reber and Evershed 2004), terpenes (Eerkens 2002, Fox et al. 1995) and sterols (Evershed, et al. 1992). These analyses of new classes of molecules provided important diagnostic tools, such as the presence of cholesterol and campesterol to identify the presence of animal and plant residues respectively.

Gas chromatography relies on molecular volatility, primarily separating molecules according to their evaporative point (Abian 1999). This limits the capacity for GC to separate low-volatility molecules, such as triacylglycerols. Triacylglycerols are the most common component of modern fats and oils forming a diverse and diagnostic class of lipid (Christie 2003, Holcapek et al. 2003, Mottram et al. 1997, Mottram et al. 2001). Triacylglycerols are composed of a glycerol backbone with three fatty acids attached via ester bonds (Figure 1a). Around 150 species of triacylglycerol would be required to account for $90 \%$ of natural variation, a much larger and more diverse range than fatty acids. Some researchers have observed the presence of triacylglycerols in archaeological residues (Charters et al. 1995, Copley et al. 2005, Dudd et al. 1999, Evershed et al. 2001, Heron et al. 1991). These triacylglycerols may provide valuable information for elucidating the original substances contributing to fatty archaeological residues and other aspects of ancient technologies. However, the technical limitations of GC-MS have meant their potential has not yet been evaluated. 
A recent advance in mass spectrometry has been the coupling of high performance liquid chromatography and mass spectrometry (HPLC-MS). HPLC is ideally suited to the separation of large, non-volatile molecules such as triacylglycerols, separating molecular species by polarity rather than evaporative point (Abian 1999). HPLC-MS can also analyse fatty acid species typically analysed by GCMS, with the advantage of a simplified preparative process. This study therefore sought to systematically evaluate the utility of triacylglycerol data derived from HPLC-MS analyses for archaeological research.

\section{Methodology}

This study utilised three datasets: (1) a set of fats and oils extracted from modern plant and animal products, based on a literature review of Anatolian archaeological finds; (2) a set of residues recovered from the fabric of purpose-built ceramics after experimental cooking of foods; and (3) an archaeological dataset of residues recovered from Late Bronze and Early Iron Age ceramics from Gordion, central Turkey (Figure 2). Fats and oils were extracted from the first dataset by ultrasonicating $500 \mathrm{mg}$ of material in $9 \mathrm{ml}$ of a 1:2 methanol/chloroform mixture for 15 minutes. The supernatant was filtered through coarse filter paper and the process repeated once. These extracts allowed the assessment of HPLC-MS separation and quantification methods, provided a baseline for comparison with experimental cooking data and provided a reference database for the interpretation of archaeological samples.

Experimental residues were prepared by boiling food products in earthenware ceramic pots for five hours. After this, the pots were allowed to cool and contents removed. The cooked-in residue was then extracted by removing a piece of the ceramic from around the 'waterline' of the pot, where the most appreciable volumes of fatty residue accumulate. The ceramic was cleaned with a

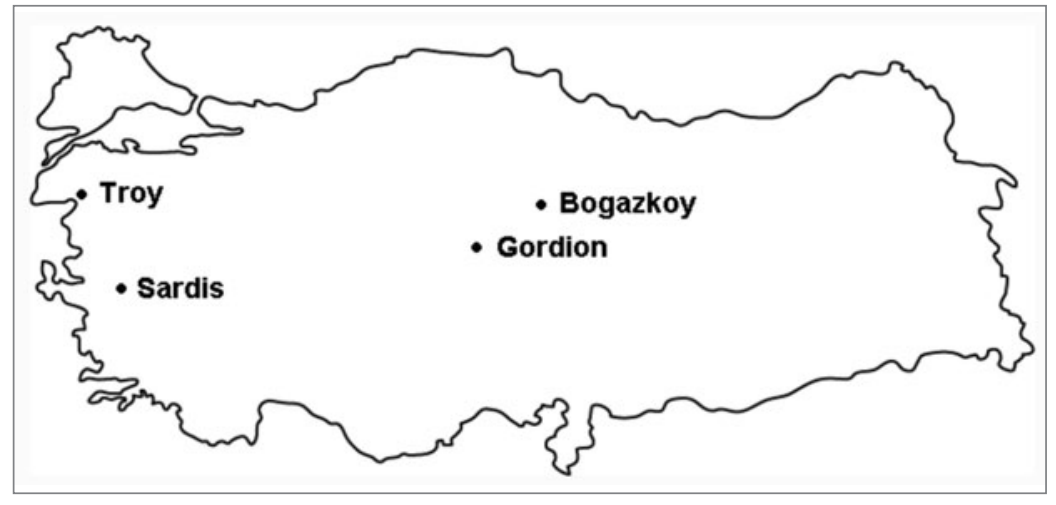

Figure 2. Location of Gordion and other key Anatolian sites. dental drill and crushed to a fine powder with a porcelain mortar and pestle. Eight grams of powdered ceramic was ultrasonicated in $36 \mathrm{ml} \mathrm{1:2} \mathrm{methanol/chloroform} \mathrm{for} 15$ minutes, followed by centrifuging at $3500 \mathrm{rpm}$. After this, the supernatant was collected and the process repeated once. The experimental database was designed to measure the effects of cooking on residues and the survivability of triacylglycerol species.

Finally, 45 archaeological ceramics were selected for residue extraction, 15 from the Late Bronze Age and 15 from each of two Early Iron Age periods (EIA 7B and EIA 7A). From these 18 were selected for residue analysis based on residue recoveries. Archaeological residues were extracted in the same manner as experimental residues. This dataset allowed the assessment of the primary focus of this study: the utility of HPLC-MS derived triacylglycerol species data for the characterisation of archaeological residues.

\section{HPLC-MS characterisation}

Residue and extract molecules were chromatographed on a Varian $150 \times 2 \mathrm{~mm}$ (i.d.) C18-A (10 $\mu \mathrm{m}$ packing) column fitted with a $20 \times 2 \mathrm{~mm}$ C18-A (5 $\mu \mathrm{m}$ packing) pre-column guard. Mass spectrometry was conducted on a Varian 1200L Quadrupole Mass Spectrometer. 
Residues and extracts were first analysed for triacylglycerols using atmospheric pressure chemical ionisation (APCI). APCI produces predictable, diagnostic parent $[\mathrm{M}+\mathrm{H}]+$ and fragment ions $[\mathrm{M}+\mathrm{H}-\mathrm{RCOOH}]^{+}$from which triacylglycerol species could be definitively identified (Holcapek et. al. 2003, Mottram and Evershed 1996). A gradient of acetonitrile (MeCN) and dichloromethane (DCM) were used as a mobile phase on the following program: 0 min - 100\% MeCN, 80 min - 100\% MeCN, $200 \mathrm{~min} 80 \%$ MeCN 20\% DCM, 210 min 80\% MeCN 20\% DCM, with a flow rate of $0.8 \mathrm{ml} / \mathrm{minute}$.

After triacylglycerol characterisation, the remaining sample was converted into free fatty acids and analysed by treating the molecules in $0.5 \mathrm{~mol}$ methanolic sodium hydroxide at $70^{\circ} \mathrm{C}$ for 3 hours. Following this, the mixture was acidified and free fatty acids extracted by washing with hexane (Christie 1987). Fatty acids were analysed using electron spray ionisation, producing detectable free fatty acid ions $[\mathrm{M}-\mathrm{H}]^{-}$with minimal fragmentation, allowing identification of molecular species by their mass and elution order. A gradient of methanol $(\mathrm{MeOH})$ and water $\left(\mathrm{H}_{2} \mathrm{O}\right)$ was used as a mobile phase on the following program: $0 \mathrm{~min}-95 \% \mathrm{MeOH} 5 \% \mathrm{H}_{2} \mathrm{O}, 26 \mathrm{~min}-100 \% \mathrm{MeOH}, 40 \mathrm{~min}-100 \% \mathrm{MeOH}$, with a flow rate of $0.05 \mathrm{ml} / \mathrm{minute}$.

Results were calculated by integrated areas of relevant molecules expressed as percentages of all lipids identified. For triacylglycerols, the integrated area of the molecular ion $[\mathrm{M}+\mathrm{H}]^{+}$and relevant fragment ions $[\mathrm{M}+\mathrm{H}-\mathrm{RCOOH}]^{+}$were summed. Free fatty acids were quantified by calculating the integrated area of the molecular ion $[\mathrm{M}-\mathrm{H}]^{-}$.

\section{Results}

\section{Food extracts}

HPLC-MS analysis of modern plant and animal products revealed complex mixtures of triacylglycerol species. From the 13 foods analysed, a total of 108 triacylglycerol species were identified. Samples contained between 21 (wheat) and 41 (pea) identifiable species of triacylglycerol, with a mean of 29.5. A total of 13 fatty acid species were identified, ranging from 6 (linseed) to 13 (chickpea, pea and wheat) fatty acid species per sample, with a mean of 10.8 .

The relative ubiquity of most fatty acid species is immediately recognisable from the dataset. Only two of the samples possessed less than 10 of the 13 free fatty acid species identified. By contrast, triacylglycerols presented a large and divergent dataset. No sample possessed more than $40 \%$ of all identified triacylglycerol species. Further, some triacylglycerol species occurred in only one sample, or a group of related samples. For example, MaSS (margaric-stearic-stearic) was found only in ruminant samples (beef and lamb), while APS (arachidic-palmitic-stearic) was only observed in pork samples. Further, MyPP (myristic-palmitic-palmitic) and PSS (palmitic-stearic-stearic) were found in all animal products studied, while plant products could generally be characterised by high levels of highly unsaturated linoleic- and linolenic-bearing triacylglycerols. Considering that the vast bulk of free fatty acids studied were derived from triacylglycerols, it is clear that reducing triacylglycerols to their component fatty acids results in a significant loss of characteristic information.

Despite the apparent simplicity of the fatty acid dataset, some simple statistics still appear to provide characteristic information. The proportion of unsaturated to saturated fatty acid species appears to differentiate modern plant and animal products (Figure 3). Animal products contained between 55 and $70 \%$ unsaturated fatty acids. This range can be reduced to 55 to $61 \%$ if chicken, which appears unusually high in unsaturated fatty acid species, is removed. Plant products possess generally higher levels of unsaturates, containing between 69 and $86 \%$ unsaturated fatty acids. Therefore, in unmodified foods the proportion of unsaturated to saturated fatty acid species seems an appropriate general indicator of plant or animal origin. 


\section{Experimental residues}

The experimentally produced residues revealed structural changes in lipid composition relative to their original plant and animal sources (Figure 4). Analysis of triacylglycerols reveals a simplification of the dataset, with only 59 of the 108 original triacylglycerols recovered from experimental ceramics. This relates to preferential destruction of the most unsaturated triacylglycerol species through the hydrolysis of the ester bond between the component fatty acids and the glycerol backbone.

Fatty acid species were similarly altered, with a general reduction in the proportion of highly unsaturated fatty acids. While volumes varied considerably, the complete removal of lipid species was uncommon. Overall the fatty acid species present remain similar to their original food products. Experimental residues contained between 9 (olive) and 13 (chickpea, wheat) fatty acid species, with a mean of 11.5. However, the relative proportions of these species are sometimes radically altered.

Comparing triacylglycerol and free fatty acid results, triacylglycerols provide more detailed characteristic markers, especially for animal products. Generally, triacylglycerols resembled fatty acids, with the preferential degradation of highly unsaturated molecules. Plant products were preferentially degraded due to the higher unsaturation of their triacylglycerol components. No sample possessed more than 55\% of all identified triacylglycerol

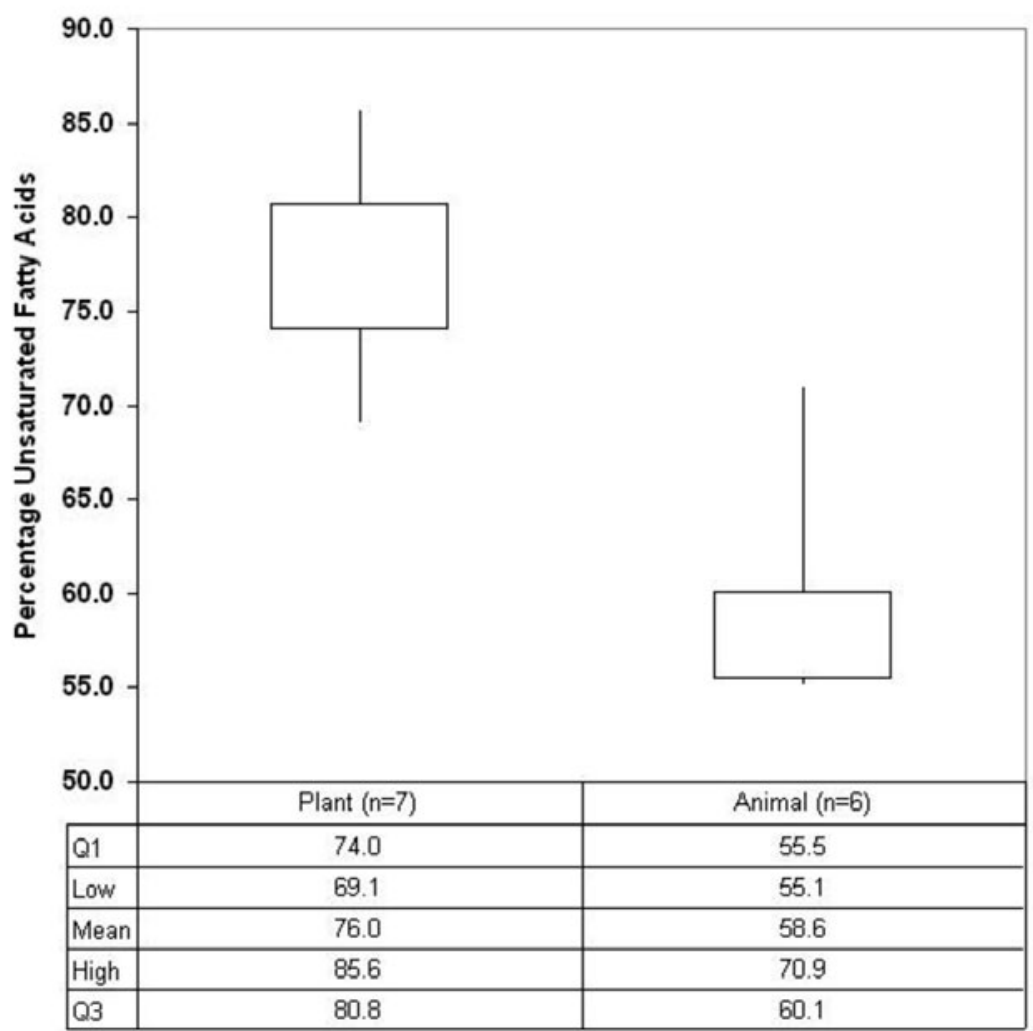

Figure 3. Boxplots of percentage unsaturated fatty acids in unprocessed plant and animal products.

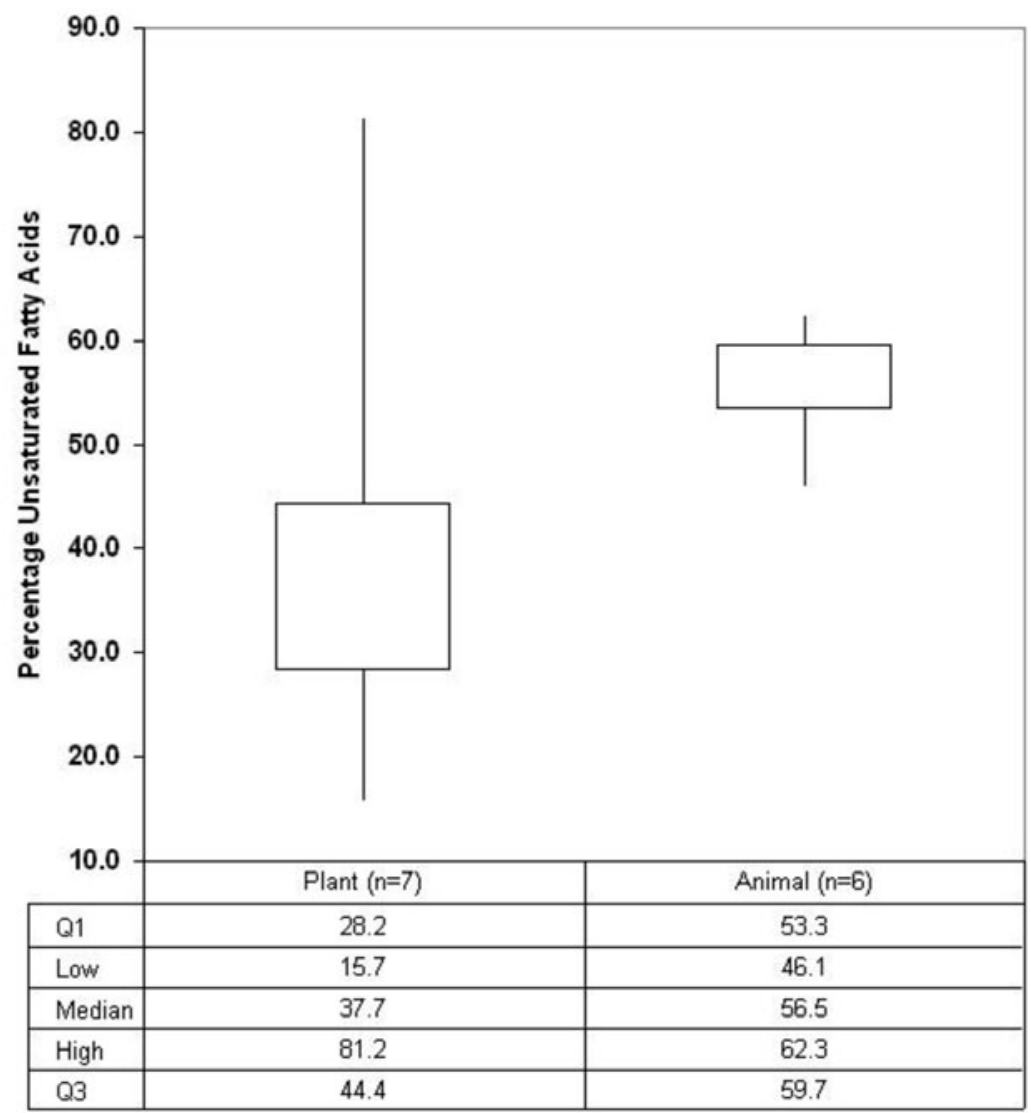

Figure 4. Boxplots of percentage unsaturated fatty acids in experimentally cooked plant and animal products. 
species, with the retention of some characteristic molecules, especially more saturated forms. In contrast, no experimental residue contained less than 9 of the 13 fatty acid species identified and only two contained less than 11.

The alteration of lipids by experimental cooking also had an interesting effect on the proportions of unsaturated to saturated fatty acids. After cooking, plant residues contained between 18 and $81 \%$ unsaturated species, compared with 69 to $86 \%$ in unprocessed extracts. Animal products contained between 46 and $62 \%$ unsaturated fatty acids. Experimental cooking seems to have removed the logical structure of the dataset noted in unprocessed extracts. While losing some unsaturated fatty acids, animal products roughly approximate their unprocessed sources. On the other hand, plant products vary across a wide range, most of which occur below the range for animal product residues. The relative instability in plant proportions most likely relates to the higher unsaturation of plant fatty acids. While most unsaturated fatty acids in animal products contain only one unsaturated double bond, plant products have much higher levels of polyunsaturated fatty acids. The susceptibility of fatty acids to degradation increases exponentially with increasing unsaturation (Eerkens 2005), rendering plant lipids more liable to degradation in the prolonged, high-energy environment of the cooking experiment.

In conclusion, the experimental dataset reveals a simplification, with the loss of characteristic triacylglycerols and free fatty acid data. However, triacylglycerols remain a diverse dataset, retaining important characteristic information. Fatty acids undergo dramatic changes in composition, rendering the proportions of unsaturates to saturates meaningless and potentially misleading. From this, it would be expected that archaeological lipid datasets would have undergone further simplification due to the effects of ancient processing and degradation over archaeological time.

\section{Archaeological residues}

Of the 18 residues analysed, only 6 contained analytically viable volumes of triacylglycerols. These residues contained between 5 and 16 identifiable triacylglycerol species, with a mean of 8 . Triacylglycerols recovered tended towards the saturated end of the spectrum, containing only saturated and monounsaturated component fatty acids. The dataset does not display the variability of the unprocessed or experimentally cooked dataset, with one residue sample containing $76 \%$ of the triacylglycerol species identified. However, by reference to the first two datasets, some of the triacylglycerols identified appear characteristic. Triacylglycerol species only observed in beef and lamb (MaSS) were present in 5 of the 6 residues, while a marker identified only in pork (APS) was observed in one sample. The sample that contained a pork marker also contained the beef/lamb marker. Markers that appeared generally indicative of animal products (MyPP, PSS) were observed in 5 of the 6 residue samples, with the one lacking these markers containing the beef/lamb marker. While this evidence is not definitive due to the limits of the reference dataset, archaeological triacylglycerols appear to provide a specific, narrow range of potential candidates for a given archaeological residue.

Fatty acids are again less informative. All 18 residues analysed contained analytically viable volumes of free fatty acids, containing between 9 and 13 fatty acid species. The potential effects of ancient reuse, mixing and differential preservation complicate the picture. However, the proportion of unsaturated fatty acids seems to reveal a logical picture. There appears to be a range separation similar to that observed in the food baseline, with an apparent separation around $25-30 \%$ unsaturated fatty acid species (Figure 5). However, the experimental dataset demonstrates that this may not be meaningful. The apparent pattern could result from a relatively predictable degradative shift of plant and animal residues, or as a false positive caused either by differential processing and degradation of a single class of product or a more unpredictable degradative process similar to the experimental dataset. Without additional data, this problem appears insoluble.

Comparison with the triacylglycerol data suggests that this difference is not simply the result of differential preservation or processing technology. If degradation differences were the cause of this spread, these degradative changes would also extend to triacylglycerols. A correlation between high 
levels of unsaturated fatty acids and the presence of triacylglycerols should be observed. The opposite is, in fact, the case. Residues that contain analytically viable volumes of triacylglycerols have generally lower proportions of unsaturated fatty acids than those without (Figure 5). This data is consistent with two distinct groups of residue undergoing degradative processes dissimilar to the experimental dataset; one predominated by animal products and another by plant products. Archaeological residues therefore underwent a different process of alteration and degradation to that simulated in our experiments. While a detailed explanation of this difference is beyond the scope of this paper, it is likely that

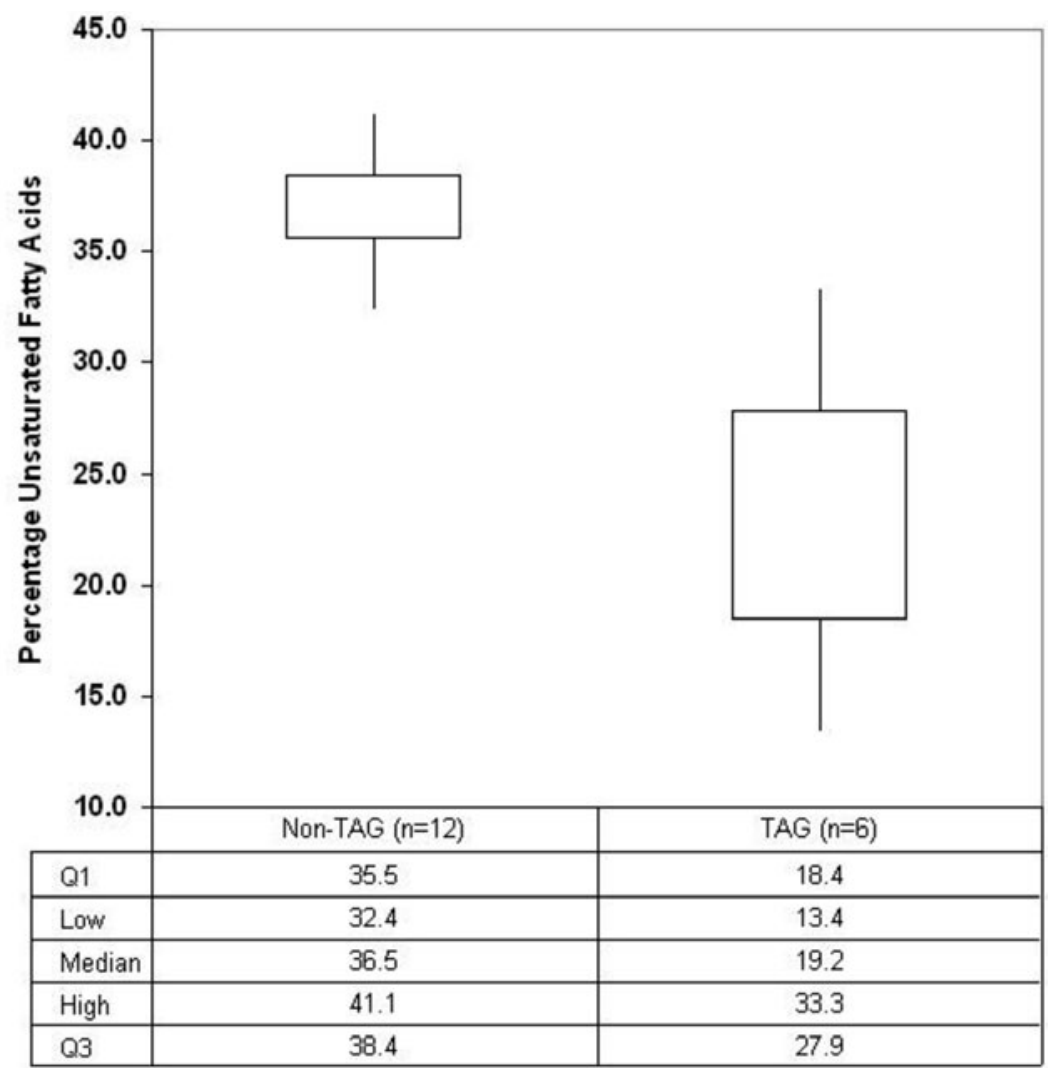

Figure 5. Boxplots of percentage unsaturated fatty acids in triacylglycerol-bearing and non-triacylglycerol bearing archaeological residues. archaeological residues were not subjected to the prolonged exposure conditions utilised in the experimental dataset. Without the benefit of triacylglycerol data, it would not have been possible to characterise archaeological residues with confidence. Triacylglycerol data therefore gives us an important new insight not only into residue sources, but also ancient processing technologies.

\section{Conclusion}

This study aimed to assess the utility of HPLC-MS analysis and characterisation of triacylglycerol species for archaeological residue research. We have demonstrated that archaeological triacylglycerols can provide significant diagnostic information, reducing the potential sources of some residues to a narrow band of related species.

Archaeological triacylglycerol data also provided important information for a puzzle presented by fatty acid data. Resolving this puzzle allows a new understanding of ancient processing technology and supporting information for the characterisation of non-triacylglycerol bearing residues. Inconsistencies between unprocessed and experimentally cooked fatty acids indicated that even a broad identification of residue contributors would be impossible for residues exposed to similar conditions to the experimental dataset. However, archaeological triacylglycerol data demonstrates a real difference between residues and a real difference in processing technology and degradation relative to the experimental dataset. The incomprehensibility of the experimental dataset calls into question previous archaeological applications of ratios used in the absence of triacylglycerol or other supporting data.

However, HPLC-MS of archaeological triacylglycerols does not provide an exhaustive method of residue characterisation. For the archaeological residues, two-thirds of the dataset would have been 
meaningless if triacylglycerol characterisation were relied on in isolation. Further, compared with GC-MS techniques where fatty acids, waxes, hydrocarbons and other classes of molecules can be analysed in a single chromatographic run, the HPLC-MS technique for fatty acid identification was less than ideal. The technique was unable to identify any classes of molecule other than fatty acids, potentially resulting in the loss of important diagnostic information.

In conclusion, HPLC-MS of archaeological fatty residues does provide significant information that could not be attained with current GC-MS techniques. Further, triacylglycerol data may reveal important details of ancient processing technologies. These advantages lead us to conclude that HPLCMS should be considered as an analytic technique for archaeological fatty residues wherever practical. However, HPLC-MS cannot be considered a replacement for established methodologies and should be used in tandem with GC-MS.

\section{Acknowledgements}

We would like to thank Dr Robert C. Henrickson and Dr Mary M. Voigt for their permission to use the ceramics in this study. The Australian Research Council supported this research with discovery grant \#DP0558992. This study was also supported by a University of New England Internal Research Grant. 


\section{References}

Abian, J. 1999. The coupling of gas and liquid chromatography with mass spectrometry. Journal of Mass Spectrometry 34:157-168.

Charters, S., R. P. Evershed, P. W. Blinkhorn and V. Denham. 1995. Evidence for the mixing of fats and waxes in archaeological ceramics. Archaeometry 37:113-127.

Charters, S. and R. P. Evershed. 1997. Simulation experiments for determining the use of ancient pottery vessels: The behaviour of epicuticular leaf wax during boiling of leafy vegetable. Journal of Archaeological Science 24:1-7.

Christie, W. W. 2003. Lipid analysis. Bridgwater: The Oily Press.

Christie, W. W. 1987. High-performance liquid chromatography and lipids. Oxford: Pergamon Press.

Condamin, F., M. O. Formenti, M. Michel and P. Blond. 1976. The application of gas chromatography to the tracing of oil in ancient amphorae. Archaeometry 18:195-201.

Copley, M. S., R. Berstan, S. N. Dudd, V. Straker, S. Payne and R. P. Evershed. 2005. Dairying in antiquity. I. Evidence from absorbed lipid residues dating to the British Iron Age. Journal of Archaeological Science 32:485-503.

Craig, O. E., G. Taylor, J. Mulville, M. J. Collins and M. Parker Pearson. 2005. The identification of prehistoric dairying activities in the Western Isles of Scotland: An integrated biomolecular approach. Journal of Archaeological Science 32:91-103.

Dudd, S. N., R. P. Evershed and A. M. Gibson. 1999. Evidence for varying patterns of exploitation of animal products in different prehistoric pottery traditions based on lipids preserved in surface and absorbed residues. Journal of Archaeological Science 26:1473-1482.

Eerkens, J. 2002. The preservation and identification of Pinon resins by GC-MS in pottery from the Western Great Basin. Archaeometry 44:95-105.

Eerkens, J. W. 2005. GC-MS analysis and fatty acid ratios of archaeological potsherds from the Western Great Basin of North America. Archaeometry 47:83-102.

Evershed, R. P., C. Heron, S. Charters and L. J. Goad. 1992. The survival of food residues: New methods of analysis, interpretation and application. New developments in archaeological science, pp 187208. Oxford: Oxford University Press.

Evershed, R. P., S. J. Vaughan, S. N. Dudd and J. S. Soles. 1997. Fuel for thought? Beeswax in lamps and conical cups from Late Minoan Crete. Antiquity 71:979-985.

Evershed, R. P., S. N. Dudd, M. J. Lockheart and S. Jim. 2001. Lipids in archaeology. In D. R. Brothwell and A. M. Pollard (eds), Handbook of archaeological sciences, pp 332-349. Chichester: John Wiley and Sons.

Evershed, R. P., S. N. Dudd, M. S. Copley, R. Berstan, A. W. Stott, H. Mottram, S. A. Buckley and Z. Crossman. 2002. Chemistry of archaeological animal fats. Accounts of Chemical Research 35: 660-668.

Fox, A., C. Heron and M. Q. Sutton. 1995. Characterization of natural products on Native American archaeological and ethnographic materials from the Great Basin region, U.S.A.: A preliminary study. Archaeometry 37:363-375.

Gariner, N. C., C. Cren-Olivé, C. Rolando and M. Regert. 2002. Characterization of archaeological beeswax by electron ionization and electrospray ionization mass spectrometry. Analytical Chemistry 74:4868-4877.

Heron, C., R. P. Evershed and L. J. Goad. 1991. Effects of migration of soil lipids on organic residues associated with buried potsherds. Journal of Archaeological Science 18:641-659.

Hilditch, T. P. and P. N. Williams. 1964. The chemical constitution of natural fats. London: Chapman and Hall.

Holcapek, M., P. Jandera, P. Zderadicka and L. Hrubá. 2003. Characterization of triacylglycerols and diacy lglycerol composition of plant oils using high-performance liquid chromatography-atmospheric pressure chemical ionization mass spectrometry. Journal of Chromatography A 1010:195-215. 
Kimpe, K., C. Drybooms, E. Schrevens, P. A. Jacobs, R. Degeest and M. Waelkens. 2004. Assessing the relationship between form and use of different kinds of pottery from the archaeological site Sagalassos (southwest Turkey) with L lipid analysis. Journal of Archaeological Science 31:1503-1510.

Malainey, M. E., R. Przybylski and B. L. Sherriff. 1999. Identifying the former contents of Late Precontact period pottery vessels from Western Canada using gas chromatography. Journal of Archaeological Science 26:425-438.

Markley, K. S. 1960. Historical and general. In K. S. Markley (eds), Fatty acids, pp 1-22. New York: Interscience Publishers.

Morgan, E. D., L. Titus, R. J. Small and C. Edwards. 1984. Gas chromatographic analysis of fatty material from a Thule midden. Archaeometry 26:43-48.

Mottram, H. R. and R. P. Evershed. 1996. Structure analysis of triacylglycerol positional isomers using atmospheric pressure chemical ionisation mass spectrometry. Tetrahedron Letters 37:8593-8596.

Mottram, H. R., S. E. Woodbury and R. P. Evershed. 1997. Identification of triacylglycerol positional isomers present in vegetable oils by high performace liquid chromatography/atmospheric pressure chemical ionization mass spectrometry. Rapid Communications in Mass Spectrometry 11:1240-1252.

Mottram, H. R., Z. M. Crossman and R. P. Evershed. 2001. Regiospecific characterisation of the triacylglycerols in animal fats using high performance liquid chromatography-atmospheric pressure chemical ionisation mass spectrometry. The Analyst 126:1018-1024.

Patrick, M., A. J. de Koning and A. B. Smith. 1985. Gas liquid chromatographic analysis of fatty acids in food residues from ceramics found in the Southwestern Cape, South Africa. Archaeometry 27:231-236.

Reber, E. A. and R. P. Evershed. 2004. How did the Mississippians prepare maize? The application of compound specific carbon isotopic measurement to absorbed pottery residues from several Mississippi Valley sites. Archaeometry 46:19-33. 